\title{
Teenage Pregnancy Strategy: Beyond 2010
}





\section{Contents}

$\begin{array}{ll}\text { Ministerial foreword } & 4\end{array}$

Executive summary 6

Chapter 1: What has changed since 1998? 12

Chapter 2: Why teenage pregnancy matters 16

and what works in reducing teenage pregnancy rates

Chapter 3: Giving young people the knowledge and skills they need to experience positive relationships and good sexual health

Chapter 4: Improving young people's access to and use of effective contraception when they need it

Chapter 5: Intervening early with those most at risk

Chapter 6: Improving outcomes for teenage parents and their children

Chapter 7: Getting delivery right - performance management of local teenage pregnancy strategies

Annex 1: Consultation questions

Annex 2: Case studies 43

Endnotes 


\section{Ministerial foreword}

We believe England's teenage pregnancy rate is too high. That was why we launched the Teenage Pregnancy Strategy in 1999. Since then there has been steady progress to the point where we have the lowest under 18 conception rate for over 20 years. Data published today shows that since the Strategy started the under 18 conception rate has fallen by 13.3 per cent with births to under $18 \mathrm{~s}$ down by almost 25 per cent. That is something which we should all welcome. It reflects a huge amount of hard work and dedication from strategic leaders, teenage pregnancy coordinators and people working in schools, youth services, sexual health clinics and wider children's services. But the job is not yet done and we need to keep up the momentum to bring down the rates to the level experienced by many other Western European countries.

The reasons why we care about reducing our high teenage pregnancy rate have not changed either. For a variety of reasons - lack of knowledge, lack of confidence to resist pressure, poor access to advice and support, low aspirations - around 40,000 young women become pregnant each year. Around three quarters of those pregnancies are unplanned and half end in an abortion - an outcome we all want to avoid. For conceptions that end in a birth, there are often costs too - poorer child health outcomes, poor maternal emotional health and well being, and increased chances of both teenage parents and their children living in poverty. These all contribute to health inequalities and child poverty.

The rationale for trying to reduce our high teenage pregnancy rate remains strong, as does our commitment to tackling the issue. This document makes clear our determination to continue to work towards the original ambition - to halve the rate of teenage pregnancy that existed in 1998 when the first phase of the Strategy was launched. It:

- takes stock of what has been achieved so far and sets out the results of work we have undertaken to review the evidence base for the Strategy and to assess its cost-effectiveness;

- sets out our vision of what we want to be provided for young people, so that they have the knowledge and skills to make safe and healthy choices, and accessible, young people-friendly services they need when they become sexually active;

- describes how all universal and targeted services for young people have a role to play in helping to prevent teenage pregnancies and provide support for teenage parents;

- looks at how we can best support and challenge local areas to drive down rates further, based on the lessons learnt from the areas where teenage pregnancy rates have fallen fastest; and

- asks for your thoughts on what more we can do to accelerate progress. 
We have reduced teenage pregnancy rates though a shared commitment between partners. We have a broad consensus now on the approach that we need to take as we move forward, which supports more open and honest discussions between young people and their parents and the professionals who support them in and out of school. If everyone is prepared to play their part, we believe as we move into the next phase of the Strategy that we can make even faster progress towards our goal.
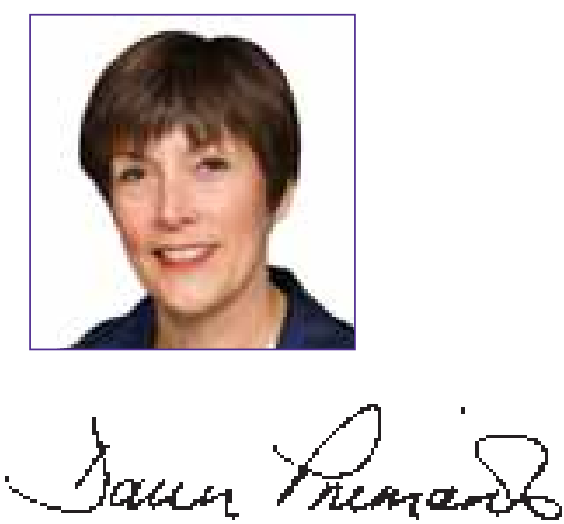

\section{Dawn Primarolo}

Minister for Children, Young People and Families
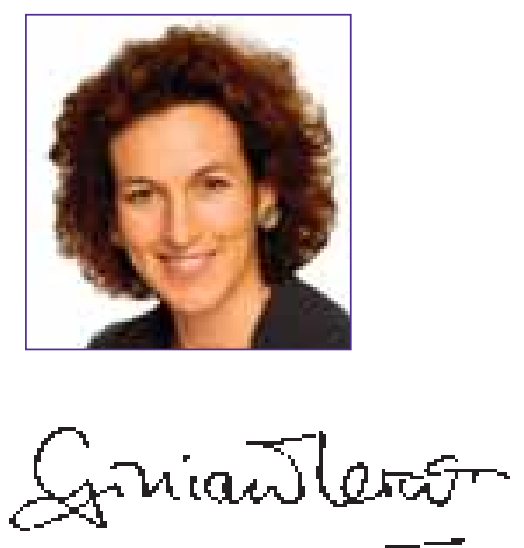

\section{Gillian Merron}

Minister for Public Health 


\section{Executive summary}

This document sets out how we want to build on the key planks of the existing Strategy so that all young people:

- receive the information, advice and support they need - from parents, teachers and other professionals - to deal with pressure to have sex; enjoy positive and caring relationships; and experience good sexual health; and

- can access and know how to use contraception effectively when they do reach the stage that they become sexually active, so they can avoid unplanned pregnancies and sexually transmitted infections (STIs).

This updated strategy document focuses on the factors we know can reduce teenage pregnancy rates when they are implemented robustly and consistently, with each delivery partner understanding and taking responsibility for their particular contribution to the overall Strategy.

The reason for issuing it now, is because - in delivery terms - the first phase of the Teenage Pregnancy Strategy was based on a target that related to 2010. This, therefore, is the final year during which local areas can take action that will influence the achievement of that target. But that does not mean that the Teenage Pregnancy Strategy ends in 2010, and so it is important that we signal to local areas the continuing priority we attach to this important issue. We will not know until 2012, exactly what level of reduction we have achieved against the target, and our commitment to improving outcomes for young people will continue.

\section{Chapter 1: What has changed since 1998?}

The under 18 conception rate is now 13.3 per cent lower than in 1998. While behind the trajectory needed to achieve the target to halve the teenage pregnancy rate by 2010, conceptions and births are at their lowest level for over 20 years. Many local areas, some in the areas of highest deprivation, have achieved impressive reductions in their local rates, demonstrating that significant improvement in all areas is possible.

During the life of the Strategy, information, advice and support for children and young people, to help them stay safe and healthy and understand the importance of relationships, has improved significantly. Young people also have better access to contraception when they reach the point at which they begin to have sex. And these changes are welcomed by the majority of parents and professionals.

But the historical reluctance to have open and honest conversations with young people about sex and relationships means that there is some way to go before we are providing the support that young people want and need. This is particularly important given the new challenges that face young people in an increasingly sexualised society. 


\section{Chapter 2: Why teenage pregnancy matters and what works in reducing teenage pregnancy rates}

Most teenage pregnancies are unplanned and around half end in an abortion. As well as it being an avoidable experience for the young woman, abortions represent an avoidable cost to the NHS. And while for some young women having a child when young can represent a positive turning point in their lives, for many more teenagers bringing up a child is incredibly difficult and often results in poor outcomes for both the teenage parent and the child, in terms of the baby's health, the mother's emotional health and well-being and the likelihood of both the parent and child living in long-term poverty.

The personal and social rationale for investment in the Teenage Pregnancy Strategy is, therefore, strong. But there is a strong economic case for investment too, with savings in public finances that exceed what has been spent on the Strategy.

The international evidence-base for the Strategy shows that the two measures for which there is the strongest evidence of impact on teenage pregnancy rates are: comprehensive information advice and support - from parents, schools and other professionals - combined with accessible, young people-friendly sexual and reproductive health $(\mathrm{SRH})$ services.

\section{Chapter 3: Giving young people the knowledge and skills they need to experience positive relationships and good sexual health}

While there have been improvements in the information, advice and support that we provide for young people on sex and relationships, there is still some way to go. Myths about sex, fertility and abortion still exist and awareness of the full range of contraception is low. A significant number of parents lack the knowledge and/or confidence to talk to their children about sex and relationships Sex and Relationships Education (SRE) in schools and post-16 learning remains patchy. And the wider children's workforce is not routinely equipped to talk to young people about their relationships and their sexual health.

Notwithstanding these remaining weaknesses, there has been progress - much of it driven by the Teenage Pregnancy strategy - and we continue to look at ways to move things forward. The aims continue to be to place understanding of sex firmly in the context of loving relationships, to help young people to resist pressure to make decisions that are not right for them and to stay healthy when they become sexually active. We have, for example, recently launched a major new media campaign Sex. Worth talking About. We are legislating to make SRE statutory and addressing the other key delivery challenges identified during the review of SRE in 2008. And we continue to support parents to talk to their teenagers. 
To accelerate progress, this document announces a number of new measures, including:

- new exemplar lesson plans for schools to help them deliver teaching on fertility and effective use of contraception, including how to access local services;

- using the Healthy Schools standard and the new enhanced Healthy Schools model to drive up the quality of SRE and support schools to develop or extend existing school-based health advice services;

- developing specialist materials as part of the Sex. Worth talking About campaign to help parents talk to their children, and a leaflet for parents that explains what SRE is and how parents can help to reinforce what their children learn in SRE at school, in the home; and

- developing training standards and materials for the wider children's workforce to better equip them to support this aspect of young people's lives.

\section{Chapter 4: Improving young people's access to and use of effective contraception when they need it}

While the majority of young people do use contraception, a minority do not and those who do use contraception do not always use it effectively on a consistent basis.

There are a number of challenges:

- Young people need to be well informed about fertility and the range of contraceptive methods available to them.

- SRH services need to be accessible - in locations young people can get to easily and open at the right times - and young people friendly.

- Professionals and parents need to reassure young people that if they are thinking about having sex, asking for contraception is the right and responsible thing to do.

There has been considerable investment in contraception over the last few years and the importance of contraception in reducing teenage pregnancy rates and improving sexual health has been highlighted in key documents setting out the priorities for the NHS and PCTs. SRH services are increasingly being delivered from a range of nonclinical locations, including schools, FE colleges and other youth settings. And the roll-out of the You're Welcome standards has resulted in SRH services in both clinical and non-clinical settings better meeting the specific needs of young people.

As with the preceding chapter, there are a number of new announcements that are designed to accelerate progress in reducing teenage pregnancy rates:

- A mini-guide for schools - produced under the auspices of the Healthy Schools programme - to encourage schools to develop or extend existing school-based SRH services.

- The development of a new decision-making contraception tool for young people that helps them to identify the method of contraception that best meets their needs. 
We are also setting out our intention to pilot in 6-8 areas in 2010/11 a one-toone consultation on relationships, contraception and sexual health with young people. This will help us to understand the barriers that currently prevent young people accessing SRH services before they become sexually active. It will test the effectiveness a pro-active offer of help at a point in time when many young people will need advice and support (the majority of young people have their first sexual experience between age 16-19).

\section{Chapter 5: Intervening early with those most at risk}

As well as improving the information, advice and support we provide to all young people, and introducing measures to ensure sexually active young people can access contraception easily and use it effectively, our success in reducing teenage pregnancy rates will also depend on how effectively we tackle the underlying factors that increase the risk of teenage pregnancy - such as poverty, low educational attainment, poor attendance at school, non-participation in post-16 learning and low aspirations.

Offering appropriate support to young people who are experiencing these underlying risk factors will help to build their resilience and raise their aspirations and so reduce the likelihood that they experience a range of poor outcomes, including teenage pregnancy. But professionals working with vulnerable young people also need to recognise the important role they can play in giving young people knowledge and skills about sex and relationships and, where appropriate, referring them to SRH services.

To ensure that professionals working within the children's workforce are clear about their role in preventing teenage pregnancies and supporting teenage parents, we will:

- publish national training standards on relationships and sexual health for local workforce training;

- identify TYS 'health' champions to ensure prevention of teenage pregnancy and improving outcomes for teenage parents are central to the remit of local TYS services;

- exemplify - in an updated version of Aiming High for Young People - how positive activity programmes can support the prevention of teenage pregnancies and improved outcomes for teenage parents and their children. 


\section{Chapter 6: Improving outcomes for teenage parents and their children}

Although our main focus is on preventing teenage pregnancies, where they do occur and the mother decides to go ahead with the pregnancy, support is provided to try to prevent the poor outcomes that are associated with teenage parenthood, including:

- poor child health outcomes;

- poor maternal emotional health and well-being; and

- increased risk of teenage parents and their children living in poverty.

Guidance issued to Local Authorities and Primary Care Trusts in 2007 set out what local areas should have in place to mitigate these risks, in particular to ensure: that maternity services are tailored to meet the needs of teenage mothers and young fathers; young mothers receive a holistic package of support, co-ordinated by a lead professional; and teenage mothers are helped to re-engage in education, employment or training.

Since 2007, a number of additional initiatives have been introduced to supplement the work that was already in place to help teenage parents and their children achieve better outcomes:

- We have expanded the Family Nurse Partnership programme - a nurse-led, intensive home visiting programme for vulnerable first time mothers aged under 20.

- We are piloting a number of models of supported housing for teenage mothers, the aim of which is to inform future commissioning of supported housing for this group of young people.

\section{Chapter 7: Getting delivery right: performance management of local teenage pregnancy strategies}

Local progress on reducing teenage pregnancy rates is variable. While 28 per cent of areas have reduced rates by over 20 per cent, around 14 per cent show an overall increase since 1998. About two-thirds of local areas have chosen reducing the teenage pregnancy rate as a local priority within their Local Area Agreements, but more needs to be done to ensure that this high-level commitment is translated into actions.

A self-assessment toolkit has been provided to local areas to help them identify strengths and weaknesses in their local strategies and local areas are encouraged to use the toolkit to develop local action plans. Government Offices and Strategic Health Authorities provide support and challenge to local authorities and PCTs, respectively. This is supplemented by consultancy visits from the National Support Team on Teenage Pregnancy, for areas facing the biggest challenges. 
To help ensure effective strategy implementation in all areas, we will:

- identify a core set of measures from the Self Assessment Toolkit and Sexual Health Balanced Scorecard which can be used by Children's Trust Boards to monitor progress and address any strategy weaknesses;

- write to SHAs and GOs to reiterate the importance of bringing down rates of teenage conceptions;

- to provide effective challenge and support, DCSF and DH will continue to work with SHAs and GOs to support improved delivery using relevant data to highlight areas of concern. 


\section{Chapter 1: What has changed since 1998?}

1.1 In 1998 (the baseline year for the Teenage Pregnancy Strategy), England had an under 18 conception rate of 46.6 per 1,000. Ten years on, the 2008 data published today confirms that the under 18 conception rate has fallen to 40.4 per 1,000 - a reduction of 13.3 per cent to the lowest level for over 20 years.'

1.2 Although the current rate of decline will leave us short of the target to halve the under 18 conception rate that we set at the start of the Strategy, it would be wrong to underestimate the significant progress that has been achieved:

- As the analysis in the next chapter shows, if the under 18 conception rate had remained at the level it was when the Strategy started, there would have been around 42,000 additional conceptions than there actually were in the last decade.

- Births to under 18s have fallen by almost 25 per cent, to their lowest level for over 20 years. $^{3}$

- Some local areas - including some of the most deprived boroughs in the country have achieved significant reductions of over 25 per cent, demonstrating that high teenage pregnancy rates are not inevitable and can be reduced through robust and consistent delivery of the Strategy, owned at senior level by all local delivery partners, with each understanding their unique contribution to the Strategy as a whole.

- Support for teenage parents has improved, helping to increase the proportion of teenage mothers in education, employment or training from 22 per cent to 33 per cent. ${ }^{4}$

1.3 The policy landscape has also changed considerably since the Teenage Pregnancy Strategy was launched. At that time, the Every Child Matters (ECM) agenda had not emerged and yet in many ways the Strategy anticipated its objectives:

- The Strategy contributes to all of the ECM outcomes - most obviously keeping children and young people safe and healthy but also through supporting young mothers to enjoy and achieve, make a positive contribution and experience economic well-being.

- The Strategy has also been at the vanguard of joint working between Government departments, local delivery partners and professionals - each with an important contribution to meeting the needs of the young person in the round. The Strategy has often been a catalyst for better health and education partnerships with, for example, school nurses contributing to school-based SRE; and schools and colleges hosting health advice services.

1.4 There has also been a shift in society's views about how best to tackle problems like high teenage pregnancy rates and poor sexual health amongst young people. Increasingly parents and professionals are recognising that we need to provide young people with: opportunities to talk openly about how they feel; the skills and confidence to deal with the real life situations they face; help to understand that the way in which sex and relationships are portrayed in the media is not always accurate; and an appreciation of the challenges and responsibilities of parenthood. This includes supporting them to delay early sex, but also equipping them to stay safe and healthy when they do become sexually active. 
1.5 There is now a clear consensus among the majority of parents and young people on the key issues:

- Young people and parents both expect that most young people will have their first sexual experience between $16-17$ years of age. ${ }^{5}$

- Young people (95 per cent $\left.{ }^{6}\right)$ and parents (82 per cent ${ }^{7}$ ) support SRE being a statutory part of the national curriculum.

- 86 per cent of parents believe there would be fewer teenage pregnancies if parents talked more to their children about sex and relationships.

- Over 80 per cent of parents agree young people should have access to confidential contraceptive services, even if they are under 16.9

1.6 There have also been significant changes to the services we provide for young people, to help them make safe and healthy choices about sex and relationships and to avoid unplanned pregnancies and STIs. In 1998, there were a relatively small number of discrete young people's sexual health services, but for the majority of young people access to contraceptive and sexual health advice was limited to their local GP or an all-age sexual health clinic. By 2007, around 30 per cent of secondary schools ${ }^{10}$ and three quarters of FE colleges ${ }^{11}$ had an on-site health service, providing advice on relationships and a range of $\mathrm{SRH}$ services. And more and more services - in both clinical and non-clinical settings - are now young people-centred, as SRH services have achieved or work towards the You're Welcome service standards, which seek to ensure that services are accessible to and meet the needs of all young people.

1.7 While there is still a long way to go, the level and quality of information, advice and support for young people has improved too. Personal, Social, Health \& Economic (PSHE) Education (which includes SRE) is judged by OfSTED to be improving overall and good in many schools..$^{12}$ Over 10,000 teachers have taken part in the national PSHE training programme. SRE is increasingly included within tutorial and enrichment programmes in Further Education. Clear and consistent messages have been promoted to young people through media campaigns. And more parents feel confident to talk to their children about sex and relationships.

1.8 It is important that we build on these positive changes in attitudes and provision as we move forward. Yet some of the barriers that account for England's high rate of teenage pregnancies persist. In particular, some media coverage of teenage pregnancy - despite the broad consensus illustrated above - remains polarised, with shock headlines that wrongly imply a large and escalating problem with no solution, which can leave professionals and parents feeling powerless to make changes. 
1.9 While the quality of advice and support, and the accessibility of services have both improved, we recognise that further improvements are needed. The challenge now is to build on progress and ensure effective delivery of all aspects of the Strategy in all areas - with each agency/professional understanding their contribution to reducing teenage pregnancy rates.

1.10 We need to ensure that the way in which we work with young people builds on the opportunities that exist and responds to the new challenges that they face. For example, the internet provides opportunities for young people to learn about relationships and sexual health in new and creative ways, and can help parents to get up to date knowledge that gives them the confidence to take on a proactive role in supporting their children. But it also means that young people's access to pornography and sexualised imagery has increased substantially in recent years. Other new technologies, such as mobile phones, can also be used in negative ways, for example to send pornographic images or to bully peers. The forthcoming Home Office report on the Sexualisation of Childhood will provide important additional insight in the pressures and challenges children and young people face.

1.11 Alcohol, and its increasing use by a minority of young people, can also increase the risk of unplanned and unprotected sex. Initial findings into the link between high alcohol consumption and teenage pregnancy suggest a strong association. Further analysis is underway to understand this better and inform effective ways to help young people recognise and manage the risks of alcohol and sexual health.

1.12 It is important therefore that - through high quality information, advice and support - we help young people to: resist pressure to have sex before they feel ready; understand the true social norms regarding young people's sexual activity (for example, that the majority of under 16s have not had sex); understand the importance of respect and mutual consent in relationships; know the difference between myths and facts; and make sense of the sexual imagery and content that they are exposed to - for example, helping them to understand that pornography can be a distorted portrayal of sex, relationships and gender roles.

1.13 We also need to ensure that we respond to new evidence about what is happening in young people's relationships, so the advice and support we provide is up to date and relevant. For example, there is a growing understanding of the worrying levels of violence that exist within teenage relationships, illustrated in a recent NSPCC survey which reported that a quarter of girls aged 13 to 17 had experienced physical violence from a boyfriend and a third had been pressured into sexual acts they did not want. ${ }^{13}$ The consequences of such violence and coercion can not only be the early initiation of sexual activity with a failure to use contraception leading to pregnancy, but also multiple sexual partners, substance and alcohol abuse and other risk- taking which can in turn lead to further pregnancy. There is also a growing understanding of the prevalence of child sexual abuse and its impact on 
sexual and future emotional health. It is therefore critical that practitioners working with very vulnerable young people - girls and boys - are aware of these issues when encouraging promotion of good sexual health. This applies particularly to those supporting children in care and care leavers.

1.14 It is clear from the evidence and the significant decline in teenage births, that the vast majority of teenage pregnancies are unplanned. It is imperative, therefore, that we reassure young people that if they are thinking about having sex, asking for contraception is the right and responsible thing to do. We must remove the apprehension, stigma and fear that deters many young people from seeking advice until it is too late. This means changing how many of us communicate with young people about relationships and sexual health: moving from silence or embarrassed conversations - often too little too late - to open, mature and well informed discussion. That applies whether the conversations are between parents and their children, professionals and teenagers or between young people themselves.

1.15 As the next chapter will demonstrate, the social and economic cases for continued investment in reducing teenage pregnancy rates and supporting teenage parents are compelling. The Strategy we have developed, and which we will build on as we move forward will continue to reflect the best international evidence. And the guidance we provide to local areas will be based on our understanding of what is driving progress in those local areas where rates have fallen fastest. Nevertheless, we do not pretend to have all the answers. That is why throughout this document we have included questions that canvass views - from Local Authorities, PCTs and the wider delivery network - on how in the context of tighter resources, implementation of the Strategy can be strengthened and taken forward beyond 2010. These questions are consolidated at Annex 1. We will be consulting separately with young people on what further support they need to experience positive relationships and good sexual health, and with parents to find out what else they feel young people need and how they can be better supported to provide it. 


\section{Chapter 2: Why teenage pregnancy matters and what works in reducing teenage pregnancy rates}

2.1 The evidence shows that children born to teenage mothers are more likely to experience a range of negative outcomes in later life and are more likely, in time, to become teenage parents themselves - perpetuating the disadvantage that young parenthood brings from one generation to the next.

2.2 Each year, around 40,000 young women under 18 become pregnant in England (around 4 in every 100 young women). The majority of under 18 conceptions are unintended and around half lead to an abortion. Where young women choose to go ahead with the pregnancy, although it is difficult to quantify the exact extent to which teenage pregnancy exacerbates existing problems, they are at greater risk of experiencing a range of poor outcomes. For example:

- teenage mothers are less likely to finish their education, and more likely to bring up their child alone and in poverty;

- the infant mortality rate for babies born to teenage mothers is 60 per cent higher than for babies born to older mothers;

- teenage mothers have three times the rate of post-natal depression of older mothers and a higher risk of poor mental health for three years after the birth;

- children of teenage mothers are generally at increased risk of poverty, low educational attainment, poor housing and poor health, and have lower rates of economic activity in adult life. ${ }^{14}$

2.3 Teenage pregnancy is a cause of health inequalities and child poverty. It is important, therefore, for local areas to understand how investing in actions to reduce teenage pregnancy and improve outcomes for teenage parents and their children enables young people to achieve their potential - increasing social capacity and producing savings in the longer-term.

2.4 Between 1998 and 2008, the under 18 conception rate has fallen from 46.6 per thousand women aged 15 to 17 in 1998 to 40.4 per thousand in 2008 . If the conception rate had remained at its 1998 level it is estimated that around 42,000 conceptions and 22,000 births would have been prevented or delayed.

2.5 Some of these conceptions would have been prevented anyway, but even if we assume that only half were directly attributable to the strategy it would have prevented or delayed over $\mathbf{2 1 , 0 0 0}$ conceptions. We expect this to have yielded a wide range of benefits, including reduced NHS costs associated with delivering fewer teenage births and providing fewer teenage abortions, as well as reduced social security payments to teenage mothers, such as income support and child benefit. Previous research suggested that if all conceptions prevented were attributed to the strategy, then for every $£ 1$ of direct investment in the strategy there could be $£ 4$ of public finance savings. ${ }^{15}$ Preventing teenage pregnancy will also have benefits to individual young women themselves and therefore the wider economy, through enabling them to spend more time in education gaining qualifications and subsequently enhancing their job prospects and earning capacity. 
2.6 However, while the savings from reducing teenage pregnancy are clear, it is also evident that investment needs to be in the right actions to have an impact. Over the last nine years, local areas receiving similar amounts of direct DCSF funding to take forward their local teenage pregnancy strategies have achieved very different levels of success in reducing their local under 18 conception rate. For example, comparing the performance of seven local authorities receiving between $£ 28-£ 29$ per young woman aged 15-17 (about the average payment), the best performing area has achieved a reduction in conception rates of 30 per cent between 200007 while the worst performing area has an increase of 6 per cent. Although DCSF funding is not the only funding that can be used in trying to reduce conception rates, this does at least suggest that local success is not simply a matter of how much areas spend, but what they spend it on.

2.7 The case for investment in teenage pregnancy prevention is strong - from both a social and economic point of view. The challenge, though, is to identify what is the right type and mix of services to invest in. For the NHS, this is crucial to meet the challenge of delivering high quality services through a period of significant financial challenge. The role of quality, innovation, productivity and prevention (QIPP) is an essential part of this process. This section aims to set out the most compelling evidence for the key planks of the teenage pregnancy strategy, and to identify priority actions which should be implemented locally.

2.8 To inform the next phase of the Strategy, an extensive review of the evidence was conducted. This will be published shortly. In summary, the international evidence identifies the delivery of comprehensive SRE programmes and provision of accessible, young people-centred contraceptive and sexual health (CASH) services as the two factors for which the evidence of impact on teenage pregnancy rate reductions is strongest. Headline findings include:

- Sex and Relationships Education: A major US study of SRE programmes found that around two-thirds of the curriculum based sex education programs studied had positive effects on teenage sexual behaviour. For example, they delayed the initiation of sex, increased condom or contraceptive use, or both. Two-thirds of the 48 comprehensive programs (supporting both delay and the use of contraceptives for sexually active teens) had positive behavioural effects. Over 40 per cent of the programmes delayed the initiation of sex, reduced the number of sexual partners, and increased condom or contraceptive use; almost 30 per cent reduced the frequency of sex; and more than 60 per cent reduced unprotected sex. None of the programmes had negative effects. ${ }^{16}$

- Contraception: 86 per cent of the decline in teenage pregnancy in the US from 1995-2002 was the result of increased use of contraception or increased use of more effective methods. The other 14 per cent was attributed to less sexual activity or delayed sexual activity. Improvements in contraceptive use included increases in the use of condoms, birth control pills, withdrawal, and multiple methods and a decline in non-use. ${ }^{17}$ 
2.9 The key challenge, therefore, is two-fold. First, we need to ensure that the information, advice and support that young people receive from parents, schools, other professionals and the internet and helplines, support young people to delay sexual activity, while also making sure that they are well-informed and motivated to use effective contraception whenever they engage in sexual activity. Secondly, we need to ensure that when they need it, there is sufficient access to sexual health and contraception services that meet the needs of young people. It is important to note that the Kirby review highlighted that young people see nothing contradictory in this combined message of delaying early sex while preparing and encouraging young people to use contraception effectively when they do become sexually active.

2.10 Above and beyond comprehensive SRE and measures to increase use of effective contraception by sexually active young people, our reviews of high performing areas and consultation with Regional and Local Teenage Pregnancy Coordinators and the DH National Support Team indicates that other factors critical to effective delivery of local strategies were:

- having local champions and senior engagement in the Local Authority and Primary Care Trust (PCT);

- investment in training for the wider children's workforce so that they have the skills and confidence to talk to young people about sex and relationships; and

- the collection, sharing and effective use of local data to inform targeted work and provide a more timely assessment of progress.

2.11 Our focus moving forward will, therefore be on improving young people's knowledge, skills and confidence - through strong, consistent delivery of SRE in schools and other settings; support for parents to talk to their children about sex and relationships; and clear and consistent media messages - alongside improving access to and use of effective contraception. Universally provided to all young people, with more intensive support for those most at risk.

\section{Consultation questions}

- How has teenage pregnancy been prioritised in your area?

- Have there been any challenges in prioritising work on teenage pregnancy?

- How are you joining work on reducing teenage pregnancy and supporting teenage parents with your local priorities? 


\section{Chapter 3: Giving young people the knowledge and skills they need to experience positive relationships and good sexual health}

3.1 The evidence is clear that giving young people knowledge about sex and relationships, and helping them develop the skills to manage relationships effectively, is protective. As shown in the previous chapter, there is strong evidence that SRE programmes help delay first sex and make it more likely that young people will use contraception when they become sexually active. The same is true for discussions between parents and their children, where open and honest communication results in children delaying their first sexual experience and subsequently using contraception more effectively. Clear and consistent messages to young people through media campaigns can also impact positively on young people's attitudes and behaviour. For example, surveys with young people have showed that those who recalled hearing the teenage pregnancy strategy media adverts were more likely to say that they would: access advice and support; discuss contraception with their partner; use contraception; resist pressure from friends; and say no to sex if they did not feel ready. ${ }^{18}$

3.2 Ideally, young people would receive their information on sex and relationships from well informed parents and teachers, health professionals and the wider children's workforce, backed up by media campaign activity that reinforces key messages. Despite recent improvements, the reality, however, is far from this ideal:

- Many young people are perpetuating myths told to them by peers and learning from negative or skewed representations of the levels of sexual activity and types of relationships in TV, films, music videos and, increasingly, pornography - all of which can increase the pressure on them to have sex before they are ready.

- While parents are young people's preferred source of information and advice, significant numbers of young people (40 per cent) report getting little or no information from them. This is especially the case for boys and young men. ${ }^{19}$

- School-based SRE is a key source of information for young people, but the quality and consistency of what is provided through SRE in schools is patchy and in many schools SRE is a low priority. A survey of over 20,000 young people by the UK Youth Parliament in 2007 showed that 40 per cent of them said the SRE they received at school was 'poor' or 'very poor'. A further 33 per cent rated their SRE as 'average'.20

- There is no formal requirement and consequently patchy provision of SRE for young people in FE colleges and work-based learning (WBL). There are examples of SRE being provided through positive activities and alternative education provision, but there is a lack of consistency of what is provided within these programmes.

- There is also a general lack of skills and confidence to discuss relationships and sexual health with young people among the wider children's workforce. 
3.3 We want to be in a position where all young people have accurate, factual information so they can make safe and healthy choices, as well as the skills and confidence that helps to ensure that they are not pressured into making choices that put their health, safety or emotional well-being at risk by having sex before they are ready. In part, this will require a cultural shift to reach a position where it is the norm for open and honest conversations about sex and relationships to take place between: parents and their children; professionals and young people; and young people themselves.

3.4 In order to reach the point where all young people feel well supported in this aspect of their lives, improvements need to be made across the piece:

- All schools, FE colleges and work-based learning providers need to be providing high quality SRE, that focuses on relationships and skills development as well as biological facts.

- Parents need to be better supported so they are confident to take on the role of providing advice and support for their children on relationships and sexual health.

- All members of the children's workforce need opportunities to develop at least a basic level of competence in talking to children and young people about sex and relationships; and those working with young people need to be aware of who is most at risk of early pregnancy.

- Young people need to be able to access reliable information via websites and helplines, which includes information on where to go for one to one advice (and treatment) on contraception and sexual health.

- Young people are supported to develop positive attitudes about relationships, including: acceptance of diversity; respect and tolerance of other people's views and choices; the importance of strong and stable relationships for bringing up children.

3.5 Action is being taken to drive forward progress on each of these areas. The new Sex: Worth Talking About media campaign is being delivered, including through high profile TV advertising. The campaign, based on the role of communications in behaviour change, ${ }_{1}^{21}$ has an over-arching aim to encourage more open and honest discussion about sex and relationships between young people, parents and professionals, with specific calls to action on chlamydia screening and use of effective contraception. Messages on sexual health and positive relationships will also be weaved into other relevant media campaigns including Why let drink decide? and the new campaign aimed at tackling violence in teenage relationships.

3.6 We are legislating to make SRE in schools statutory throughout Key Stages 1-4, as part of planned programme of PSHE Education. The new statutory duty on schools will be underpinned by statutory programmes of study; and exemplified through new SRE guidance for schools in September 2010. While there are excellent examples of comprehensive SRE in schools, making SRE statutory will raise the status of the subject in all schools and the statutory programmes of study will help to ensure all children and young people receive a more consistent offer. 
3.7 Making SRE statutory is essential to raise the profile of this important aspect of young people's learning and development, but it needs to be combined with other measures to drive improvements in its quality. The biggest delivery challenge identified by the SRE review in 2008 was the need to improve the skills and confidence of those who deliver SRE. In response we have been working with the Training and Development Agency to ensure both a stronger focus on PSHE within all initial teacher training (ITT), as well as creation for the first time of a route through ITT to become a specialist PSHE teacher for those joining the profession. At the same time, we are continuing to fund participants on the national PSHE Continuing Professional Development programme, which has trained around 10,000 teachers over the last seven years.

\subsection{Other measures designed to tackle weaknesses in SRE delivery include:}

- creating a stronger 'learner voice' in the provision of SRE through, for example, promotion of the SRE pupil audit toolkit Are you getting it right, which allows young people to comment on the extent to which the school's current SRE programme is meeting their needs, as well as shape the programme for the future;

Walsall Children's Services, Serco, NHS Walsall and Walsall Council completed a large scale audit of pupils views of school SRE. Using the SRE audit toolkit, 13,000 children and young people gave their views on the topics they most wanted at different ages and how they would like SRE taught. The findings are being disseminated to all schools to help shape SRE that meets pupils' needs, as well to the wider children's workforce.

- better measurement of young people's perceptions of SRE through both the national Tellus survey, and the wellbeing data for the School Report Card, which will be used by Ofsted to inform their assessment of the school's performance on supporting young people's wellbeing.

- identifying and sharing targeted SRE programmes effective in engaging young people most at risk, such as the innovative L8R programme;

The award winning L8R project integrates interactive drama on video and the web, access to advice and information and online mentoring. The TV drama episodes aim to raise awareness, challenge attitudes and prompt discussion about sexual health and teenage pregnancy as well as drugs and alcohol, peer pressure and gangs. Used in over 300 schools, L8R is also popular with PRUs and Youth Offending Teams to engage more vulnerable young people. 
- making the case for SRE by helping people to understand what SRE is and how it helps to keep children and young people safe and healthy, for example by developing an SRE briefing for school governors. This will help to counter the many myths about SRE;

- developing lesson plans for schools on improving young people's knowledge and understanding of fertility, effective use of contraception and how to access local services - in recognition that awareness among young people of the full range of contraceptive choices is low;

- strengthening the self-validation process for achieving Healthy Schools Status in relation to SRE provision by ensuring that, if appropriate, the local authority quality assurance system includes someone with expertise on both SRE and increasing use of contraception;

- where schools are working on the enhanced model for Healthy Schools and choose to focus on teenage pregnancy, the local quality assurance system should test with schools that the SRE is meeting the needs of children and young people: that pupils are provided with up to date factual information on the full range of contraception; and pupils receive guidance on how to access local services and what to expect from local clinics and GPs in relation to contraception; and

- encouragement and support through the Healthy FE programme to ensure SRE is successfully included in FE tutorial and enrichment programmes and, through Brook, promote the Sex Worth Talking About and Why Let Drink Decide media campaigns in FE settings.

3.9 Helping parents to play a more pro-active role in supporting their children on sex and relationships is critical. All the evidence points to parents being the key influencers of their children's attitudes and behaviours, so positive messages from parents about not being pressured into making choices that are not right for them and stressing the importance of safe sex will help to reduce teenage pregnancy rates.

3.10 As part of the Sex: Worth Talking About campaign, we will be developing materials aimed at parents to support them in having conversations with their children about sex and relationships - through web-based materials and leaflets.

3.11 In order to counter the sensationalist headlines about SRE, we will be publishing a leaflet aimed at parents which: explains what, in reality, is taught in SRE in each key stage; why it plays an important role in helping young people to resist pressure and in keeping them safe and healthy; and which encourages parents to use the learning their children receive at school as a prompt for discussion at home. 
3.12 We will also be consulting parents to better understand what further advice and support they would like to help them to talk to their children about sex and relationships. This will inform the development of specific support on this issue, but we will also be incorporating advice to parents on SRE issues in a wider parenting support booklet, and in guidance for schools and local authorities on parental engagement more broadly.

3.13 And from the roll out of the fpa 'Speakeasy' programme which gives practical support to groups of parents on talking to their children about sex and relationships, we will share the learning on incorporating the lessons in wider parenting strategies.

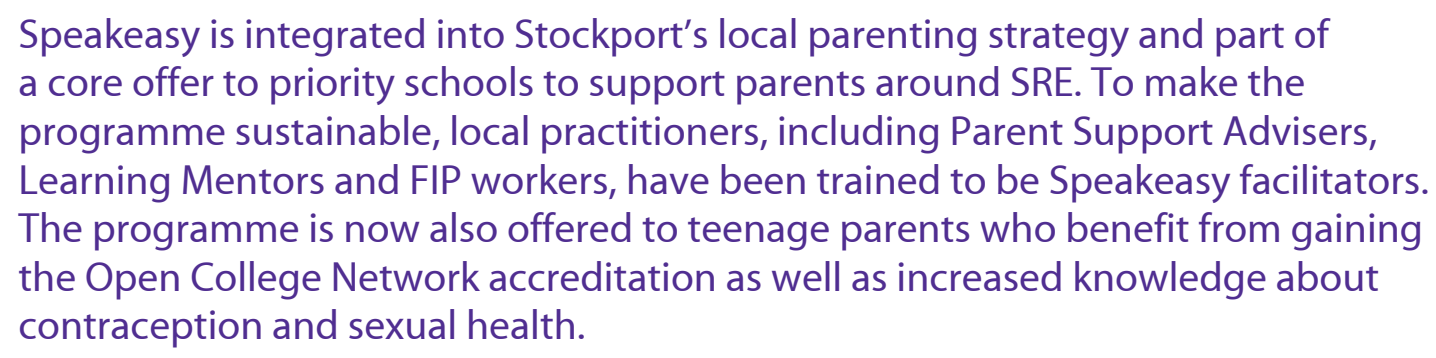

3.14 We believe it is vital that we improve the skills and confidence of the wider children's workforce, many of whom are working with those young people who, because of underlying risk factors, are at higher risk of early unprotected sex and teenage pregnancy. The revision of the 'common core' of knowledge and skills will include the expectation that all those working with children and young people can identify early the risk factors for early pregnancy and understand how to refer them for appropriate information, advice and support services.

3.15 To support the Common Core, we will develop national training standards on sexual health and relationships to provide a consistent framework for local workforce development. We will work with Children's Trusts to ensure induction for members of the children's workforce includes identifying risk factors for teenage pregnancy and signposting of young people to specialist advice.

3.16 We will undertake some qualitative research with practitioners working with young people to understand better their knowledge and attitudes towards teenage pregnancy and the contribution of their role. The findings will inform both training and communications to the wider workforce. 
Warwickshire has set up a Relationships and Sex Education policy with a four tiered workforce training programme under the umbrella of the county's Respect Yourself Campaign. 1,000 staff have attended, with 350 staff from education, IYSS, leisure, police and the voluntary sector trained to level 3. In one persistently high rate borough, where training for frontline workers was prioritised, under 18 conception rates have begun to fall.

\section{Consultation questions}

-What are your local actions to improve children and young people's knowledge and skills on relationships and sexual health through: SRE in schools, FE, parents, and the wider workforce?

- How are you measuring the impact this has had?

- Are there any national actions that could be taken to help you accelerate progress?

- What existing local arrangements for involving young people could be used to ensure the SRE - in schools and other settings - are meeting their needs? 


\section{Chapter 4: Improving young people's access to and use of effective contraception when they need it}

4.1 In the majority of cases, using contraception effectively will prevent a pregnancy and, additionally, using condoms will normally prevent someone from getting an STI. The challenge, therefore, is to ensure that:

- young people feel that asking for contraception if they are sexually active is the right and responsible thing to do;

- young people who are sexually active are using a method of contraception that is right for them, and that they are motivated and supported to use it effectively and consistently;

- sufficient sexual and reproductive health (SRH) services exist to meet demand, and that these services are working to meet the You're Welcome criteria to ensure easy access - in terms of location, opening hours, confidentiality, friendly staff and young people involvement.

4.2 The preceding chapter set out the measures we are taking to help young people avoid being pressured into sex before they are ready, to ensure that when they do become sexually active they understand the range of contraceptive methods available to them and how each works to prevent pregnancies and protect their sexual health, and know where to access local services if they need advice. This chapter focuses on what we are doing to ensure that young people are able to access services which they feel confident to use.

4.3 The majority of young people do use contraception, most of the time. But some young people do not access advice and support before they have their first sexual experience, and/or do not use contraception consistently thereafter. A survey of women who had had an unintended pregnancy (Marie Stopes) showed that 37 per cent had not been using contraception at the point of conception. Of these, 42 per cent cited user-related issues and 29 per cent cited method-related reasons. Only eight per cent cited lack of access.22 A further survey of young people (Unicef) found that while 56 per cent of respondents who had accessed a sexual health service had a positive experience, 22 per cent found it to be bad or very bad. The same survey found that 70 per cent of young people who had had unprotected sex did not think they needed to visit a sexual health service. ${ }^{23}$

4.4 It is imperative that we make every effort to encourage all young people who are sexually active to use a form of contraception that suits their circumstances. For this to happen, young people need to be motivated to address their reproductive and wider sexual health needs and to consequently choose and use contraception effectively, including condoms to prevent STI transmission. And healthcare professionals, and other professionals working with young people, need to be aware of sexual health issues including the choices of contraception available and be able to either support young people in making their choice, or signpost young people to 
specialist contraception and sexual health services. Critically, all professionals need to convey positive and welcoming messages to young people to allay the fear of being judged that deters many from visiting services.

4.5 Beyond these issues of awareness and knowledge, young people also need to be able to access SRH services at times and in places which fit with their daily lives, in an environment that is confidential and young people-centred and which offers the full range of contraceptive methods.

4.6 There are a significant number of actions that have been put in place in recent years to improve sexually active young people's access to, and uptake of effective contraception. First, we have sought to ensure that the importance of contraception in reducing teenage pregnancies is reflected in key documents that set the priorities for the NHS; and that the data exists to allow effective performance management of each area's progress:

- Reducing teenage pregnancy rates is a Tier 2 Vital Sign in the NHS Operating Framework. The Operating Framework specifically refers to the contribution that contraception can make to meeting teenage conceptions targets.

- From 1 April 2009, GPs were provided with additional incentives, through the Quality Outcomes Framework, to provide advice on sexual health - specifically advice on contraception, and particularly long acting methods.

- There have been improvements in the sexual health data available to local areas to help them to monitor their performance more effectively and to reconfigure current provision where this is necessary. In particular, the Sexual Health Balanced Scorecard has been developed by the South West Public Health Observatory in collaboration with the Health Protection Agency and contains a set of main and supporting sexual health related indicators for each Primary Care Trust in England. In addition, the Sexual and Reproductive Healthcare Activity Dataset (SHRAD) has recently been approved by the Information Standards Board. SHRAD has been developed and introduced to modernise the collection of data relating to sexual and reproductive health and to monitor activity at PCT level to enable commissioners to understand which of their population groups are accessing services and the care they are receiving.

- Also from 1 April 2009, the standard NHS Contracts for the provision of abortion services have included a requirement that all clients should receive advice on contraception. 
At a national level, 11 per cent of abortions to under 19s are repeat abortions - but this rises to almost 20 per cent in some areas. We will be sharing effective practice from areas, such as Hackney, which are starting to see the impact of specific work to help young people prevent repeat abortions.

To help reduce repeat conceptions, Hackney has appointed an Assertive Outreach Nurse. Young people who have had a baby, abortion or miscarriage are referred to the nurse by maternity and other services, and helped to choose and use effective contraception. Key aspects of the role are perseverance, being young people friendly and having the flexibility to meet young people at times and locations that suit them. Between 2007 and 2008, the number of repeat abortions fell from 47 to 29.

4.7 There has also been significant additional investment in contraceptive services. In 2008/09, PCT budgets were increased by $£ 12.8$ million to help them to improve local SRH services. This was supplemented by additional money to Strategic Health Authorities (SHAs), which PCTs could bid for to 'pump-prime' further improvements. This "Improving Access to Contraception Fund" was available for the three years $2008 / 09$ - 2010/11 to help to support the development of sustainable contraception services. This funding amounted to $£ 10$ million in 2008/09 and $£ 10$ million in 2009/10, with additional sums specifically for improving services in FE colleges of $£ 1$ million in 2008/09 and $£ 1.6$ million in 2009/10.

4.8 This investment has seen a significant increase in workforce training in fitting and removing Long-Acting Reversible Contraception (LARC) methods. For example, West Midlands SHA has taken a cross region collaborative approach to training, which has allowed areas with fewer LARC trainers to take advantage of training expertise from across the Region. In North East Lincolnshire, through a partnership between the PCT and the local authority a mobile unit and driver (funded by the local authority) staffed by nurses (funded by the PCT) is used to reach vulnerable young people who are not accessing mainstream services. The young people are identified through partnership working with key organisations in the area, particularly the youth service and drug and alcohol teams. And in Solihull, the additional funding for contraception has resulted in a specialist nurse who leads on improving LARC uptake among young women, particularly following abortion. The nurse also leads on raising awareness of contraception, particularly LARC among clinical colleagues, including those working in primary care. 
4.9 There has also been significant support for local SRH services to ensure that the services they provide are attractive to young people, in particular by supporting SRH services to work towards achieving the You're Welcome quality service criteria, which set out best practice in the provision of health services for young people, including sexual health services. A regional support network helps commissioners and providers of health services to apply the criteria consistently. Uptake has been promoted in both NHS and non-NHS health provision so that, wherever they live, young people are able to access services that meet their needs. Health services on or near education premises have been an initial priority.

The Ridge Medical Centre in Bradford is one of the first general practices to achieve You're Welcome accreditation. Young people have been involved in the design of a specific youth space and participate in the Practice's patients group. A wide range of contraception and STI treatments are provided, and a weekly drop is also open to young people not registered with the practice.

As part of the core support offered to local areas on sexual health service improvements, Government Office North West and NHS North West have commissioned young advisers from Knowsley to be mystery shoppers of local services. Using the You're Welcome criteria as the framework, the young advisers provide feedback to senior strategic leads in the LA and PCT.

4.10 And there has been significant reconfiguration of services in many areas so that services are in locations that young people spend their time and are open at times that young people find convenient. As part of the wider NHS agenda, an enhanced role for community services is being taken foreword, with the shifting of care out of acute services and closer to home.

4.11 A key focus of this reshaping of local services has been the development of SRH services in education settings. A mapping survey carried out by the Sex Education Forum in 2007 identified that around 30 per cent of Secondary Schools and around three quarters of FE colleges had some on-site provision. The additional funding referred to in paragraph 4.7 above has been focused on both: developing services in more schools and colleges; and extending the breadth of services provided in them - especially to extend the range of contraception methods that are available. We have published good practice guidance on how colleges and PCTs should work together and take a strategic approach to the development of sexual health services on FE College sites. Anecdotal evidence suggests that services based in non-clinical settings are more appealing to boys and young men and young people from some BME groups. 
Supported by the appointment by NHS Blackpool of a full time health mentor, Bispham High School - Arts College has set up a school based health service, including a weekly sexual health clinic. In the two years since the introduction of the clinic, only one student pregnancy has been recorded, compared to 16 in the previous two years. In 2009 the on-site service was one of the first to achieve You're Welcome accreditation.

Southampton has set up a weekly sexual health drop in at each of their FE colleges, as part of a larger health and well being service. Provided by a local voluntary organisation and specialist sexual health nurse, the service offers the full range of contraception, condoms, chlamydia screening and pregnancy testing. The nurse and student support staff also work together to identify students who may be at higher risk and benefit from additional SRE.

4.12 In order to maximise the potential of schools that choose teenage pregnancy as a priority when working towards Enhanced Healthy Schools status, we intend to provide them, and other schools wanting to set up on-site services, with a miniguide: this will look at barriers to establishing sexual health services that meet the standards set out in You're Welcome, on or around the school, and identify solutions and ways forward for the school.

4.13 A number of recent initiatives have helped to ensure that SRH services improve the way in which they support young people to understand the choices open to them and make the choice of contraception that is right for them, including:

- a contraception decision making tool for all adults, including young people. The guide will give users a number of different options for contraception, together with reasons for why these options have been recommended. This will shortly be published by Brook and fpa, with a link from the Sex. Worth Talking About campaign website;

- NICE Public Health Intervention Guidance, which recommends that midwives and health visitors who work with vulnerable young women under the age of 18 who are pregnant or who are already mothers should provide these young women with advice on contraception, including LARC methods; and

- a specific guide to pregnancy for young women from the charity Tommy's. The guide A Young Woman's Guide to Pregnancy is designed to be used by women under the age of 20 and was produced in conjunction with young people. It is used by both young women and the healthcare professionals who work with them, and covers information on post-natal contraception. 
In addition we will:

- develop, in partnership with relevant stakeholders, a Competence Framework for sexual health nurses. This will identify the skills, experience and training which are needed to ensure consistency and quality across healthcare in England. The framework will identify the skills and competences required by sexual health nurses at entry-level and up to and including advanced/Nurse Consultant levels;

- examine ways in which existing guidance and local effective practice on offering post-natal contraception to young mothers can be applied more consistently - to reduce the number of repeat conceptions. An estimated 20 per cent of births conceived to under 18 s are to young women who are already mothers;

- evaluate and share effective practice on brief interventions on alcohol with young people in sexual health services; and

- publish a world class sexual health commissioning framework, covering all aspects of sexual health including contraception, abortion, STIs and HIV. The framework will be structured around the commissioning cycle and will provide a wide range of information including national guidance, model specifications for different levels of service provision and local examples of good practice and innovative working, and will cover the provision of contraception for young people. This framework will help all areas develop excellent commissioning arrangements, such as the example from North Tyne.

To accelerate reductions in teenage pregnancy, North Tyne, covering Newcastle, North Tyneside and Northumberland PCTs, has prioritised improving young people's access and uptake of effective contraception, with a particular focus on Long Acting Reversible Contraception. Commissioning includes a Local Enhanced Service for LARC in Primary Care and in six community pharmacies; a peripatetic nurse to reach young people at risk; contraception training for nurses in abortion services; and on-site services in FE colleges.

4.14 Condoms remain the only way to protect sexually active young people against STIs. They also remain the most widely accessible form of contraception, as well as the only kind that can be used by men. It is therefore important that the promotion of condoms remains central to the overall effort to improve the take up and effective use of contraception. So a number of activities to improve condom use are being undertaken including the piloting of vending machines in places that provide a range of condoms and other services and which are accessible to target groups. With our support, Brook will also shortly be publishing new guidance for local areas on effectively supporting boys and young men to use contraception and look after their sexual health. 
4.15 It is important too that we do not see prevention of unplanned pregnancies in isolation from other initiatives to improve young people's broader sexual health. Consequently we have been using the National Chlamydia Screening Programme (NCSP) to create opportunities for promotion of effective contraception to young people, so that they receive the range of information and support they need to protect their sexual health through a single intervention. The importance of joined up support on contraception and sexual health is central to the messages to young people and professionals in the Sex. Worth Talking About media campaign.

4.16 While there has been significant action over the last few years to improve access to and uptake of contraception by young people, these measures are not always reaching young people when they need them. And we still have some way to go to reach a point where all young people are well informed about their choices.

\subsection{Therefore, in addition to the measures already outlined to improve} information, advice and support and access to contraception, in 2010/11, we want to pilot in 6-8 local areas the offer of a one to one consultation on contraception and sexual health to young people - girls and boys - in Year 11 (15-16). This would seek to ensure that young people participating in the pilots had a personalised discussion about contraception and sexual health to: allow them to ask questions about relationships and discuss any pressures to have sex; increase awareness and use of effective contraception among those who are, or are about to become sexually active; and raise awareness of preventing STIs. The offer of a one to one consultation would aim to close the gap between young people receiving SRE in school and finding their own way to services, during which time many risk unprotected sex. It would also seek to provide a bridge from group SRE lessons to a confidential conversation tailored to their individual circumstances, providing immediate help on contraception and sexual health for those who are having sex, and preparing others for when they choose to become sexually active in their later teens. We are working with local areas to identify potential pilot sites, the number of pilots and the level of funding each will receive. An evaluation team will be appointed.

\section{Consultation questions}

- What are your local actions to improve sexually active young people's access to effective contraception and condoms?

-What are your local actions to improve sexually active young people's use of effective contraception and condoms?

- Are there any national actions that could be taken to help you accelerate progress?

- What existing local arrangements for involving young people could be used to ensure local contraceptive and sexual health services are meeting their needs? 


\section{Chapter 5: Intervening early with those most at risk}

5.1 While the actions of the Teenage Pregnancy Strategy need to reach all children and young people, local delivery needs to ensure that young people most at risk receive early and effective support. These include young people with low educational attainment, dislike of school and poor attendance, in contact with the police, poor emotional and mental health, and those living in and leaving care.

\subsection{The Children's Plan set out our commitment that all areas should have} consistent, high quality arrangements across all services (including schools, children's services and health and youth justice services) that provide identification and early intervention for all young people who need additional help. These arrangements, described and promoted under the heading of Targeted Youth Support (TYS) reforms, seek to address the underlying risk factors that can result in a range of poor outcomes, including those that can arise from early unprotected sex and teenage pregnancy.

5.2 Services for young people, organised in this way, help in developing resilience and raising aspirations amongst vulnerable young people, building on the work that schools and colleges do. Raised aspirations and skills in resilience have a direct influence in reducing the full range of poor outcomes, including teenage pregnancy, and so make a crucial contribution to supporting the strategy in their own right. But to have the maximum impact on reducing teenage pregnancy, the services delivered under TYS arrangements need to include specific actions which provide young people with the knowledge and skills they need to experience positive relationships and good sexual health and to promote access to the contraception that they need, when they need it.

5.3 It is therefore important that all professionals providing support for vulnerable young people play a full part in action that will have a direct impact on reducing teenage conceptions. Even where their main function may not explicitly be about helping young people to prevent unplanned pregnancies or STIs, they nevertheless need to understand that they all have a role to play. This is both about being able to proactively provide advice and help young people to access specialist services on matters directly to do with sexual health and about identifying risk factors and providing wider support with personal skills and in building ambitions to stay on a path to success.

5.4 The strengths of relationships with parents continue to be very important to teenagers, albeit that the nature of the relationship inevitably changes. But, as part of the process of developing their independence, young people increasingly turn elsewhere for sources of information and support. The skills of professionals in developing a relationship of trust with young people put them in the position where they can be alert to any evidence that the young person is facing pressure to be sexually active or putting themselves in situations where they are at risk of unplanned pregnancies and STIs. For example, an admission by a young person that they were drunk the night before might lead to a discussion with the lead 
professional about the risks they had exposed themselves to. That in turn might prompt a conversation which the professional needs to be ready to use to full advantage about pressures to have sex or the need for contraception and support to access specialist contraceptive and sexual health advice.

5.5 Lead professionals also play an important role in helping teenage parents and their children have better outcomes. This might mean helping a teenage mother to re-engage in education, employment or training. Part of that support role should include helping young mothers to access effective contraception, to avoid repeat unplanned pregnancies.

5.6 To ensure that this sort of support is in place, we want prevention of teenage pregnancy and support for teenage parents to be a clear priority for Children's Trusts and to be fully part of Integrated Youth Support Services. This means that:

- Prevention of teenage pregnancy and support for teenage parents should be a key consideration for Children's Trusts when commissioning Information Advice \& Guidance (IAG) services, Targeted Youth Support and positive activities.

- Children's Trusts should consider what specific services and activities they need to provide to support this agenda as well as considering how teenage pregnancy and sexual health issues might be addressed in delivery of more generic universal or targeted provision.

- The children and young people's workforce should be adequately trained in these issues and know how to identify risk and where to signpost young people to more specialist support.

5.7 To support these priorities, we will publish national training standards on sexual health and relationships to provide a consistent framework for local workforce development. This will help areas ensure that practitioners working within Integrated Youth Support Services, the provision of positive activities and TYS arrangements are aware of young people at risk and have the knowledge and confidence to discuss sexual health issues and link young people into local RHS services.

\subsection{To get the maximum contribution from TYS, the consultancy support} to local areas that is available for the remainder of this year will be ensuring that prevention of teenage pregnancy and support for teenage parents is fully integrated into local TYS arrangements. To take this work forward, one of a new set of TYS 'champions' will lead on health issues. Appointed on the basis of their health expertise they will help areas integrate teenage pregnancy actions, including the stronger focus on SRE and contraception described earlier, and the sharing between areas of best practice on both early identification and effective support, such as the example from Stoke. This focus on teenage pregnancy will be included in an updated Guide to TYS for local areas, to be published in the summer. 
Stoke-On-Trent City Council has appointed six dedicated Teenage Pregnancy Prevention Officers, developing a screening toolkit to support identification of young people at risk. The team provide one to one, group and drop in sessions focused on raising self esteem as well as helping young people access sexual health advice. Since September 2007 the Prevention Team have provided intensive support to 272 young people at 'high risk' of early pregnancy, only 13 of whom have become pregnant.

5.9 We will have more to say in the coming weeks about the development of the services for young people in general. In an update to Aiming High for Young People we intend to give strong recognition to the progress that local authorities have made in recent years on this agenda, to set out a clear articulation of our developed understanding of what works, exemplified by examples of good practice, such as Sunderland, and to set out the case for next steps. This will highlight the importance of integrated youth services - prevention and support - in local commissioning arrangements and include examples of good practice on teenage pregnancy.

Sunderland Mobile Youth Villages are a new concept to engage young people in positive youth work activities at the weekend. Events take place at six venues throughout the area, staffed and controlled by a large team of qualified Youth Workers. Activities are offered in enclosed areas and include football tournaments, a climbing tower, DJing, street dance, and game consoles. Alongside this, a caravan for youth information which focuses on sexual health issues, drug and alcohol advice as well as career aspirations is also part of the events.

5.10 We will also shortly be publishing a document on early intervention to help Children's Trust Boards develop and commission effective early intervention arrangements as part of their Children and Young People's Plans. This will provide examples of the benefits of early intervention on teenage pregnancy.

\section{Consultation questions}

- What is working well on early identification and integrating teenage pregnancy actions into support for young people at risk of pregnancy?

- Is CAF being systematically used?

- How are you measuring impact of early intervention and support for young people most at risk of pregnancy? 


\section{Chapter 6: Improving outcomes for teenage parents and their children}

6.1 Reducing our historically high level of teenage pregnancy has been and continues to be a top priority for this Government. But we have also taken unprecedented steps to ensure that where young people do become parents they get the support they need to make successful futures for themselves and their children. This is in no sense about encouraging early parenthood, nor is there any evidence to suggest that the support we have put in place had had this effect. The almost 25 per cent reduction in births to under 18s suggests the opposite. But it is recognition that extra support is needed if we are to break the intergenerational cycle of low aspirations and poor outcomes associated with early parenthood.

6.2 Like all parents, teenage mothers and young fathers want the very best for their children and some manage very well. But the demands of caring for a baby at a time when young people themselves are making the transition from adolescence to adulthood are significant and can contribute to the poor outcomes that many of them experience. For example, they experience 60 per cent higher rates of infant mortality, have three times the rate of post-natal depression compared to older mothers, and there is a greater risk for them and their children of living in poverty in later life. ${ }^{24}$ What is clear is that these poor outcomes are not inevitable if early and sustained support is put in place.

6.3 As with effective strategies to reduce teenage pregnancy, the solution to improved outcomes for teenage mothers, young fathers and their children, rests with a range of services working together across the NHS, Local Authorities and the voluntary sector. The key ingredients of effective support are early identification and needs assessment in the antenatal period and dedicated, sustained support from a lead professional - a 'critical friend' - coordinating and drawing in specialist services as needed. Referral pathways between maternity services and on-going support need to be clearly understood and watertight to prevent teenage mothers and young fathers slipping through the gaps between services and missing the support they need. And critically, all professionals and services need to be proactively welcoming to young parents to dispel the apprehensions which deters many of them from accessing the very services they need.

6.4 Whilst the exact arrangements for providing coordinated support are a local decision, we have issued best practice guidance to LAs and PCTs that sets out what should to be in place to improve outcomes for teenage mothers and young fathers. In the antenatal and immediate postnatal period services should be commissioned and information sharing protocols developed against the principles of our guidance Teenage Parents: who cares? and Multi-agency working to support pregnant teenagers. To ensure sustained and coordinated support, local areas should 'design in' teenage parents to Targeted Youth Support arrangements so that systems are in place for early identification and on-going support through a lead professional. To ensure a strong focus on improving young parents' confidence and engagement in education, teenage mothers and young fathers should also be included as a priority group in the commissioning of Information, Advice and Guidance (IAG) and positive activities programmes. Children's Centres and parenting strategies should review the extent to 
which they are reaching teenage parents, identify gaps and shape services to ensure that they meet their needs. And we have made clear that no teenage mother under 18 , who cannot live at home, should be given an independent accommodation without adequate support being in place.

6.5 To help understand the most effective way of supporting teenage parents, we are also taking forward and evaluating more intensive models of support through the Family Nurse Partnership (FNP) and the Teenage Parents Supported Housing pilot. FNP is an intensive, nurse-led preventive home visiting programme for vulnerable first time mothers, mostly under 20, starting in early pregnancy and continuing until the children are two years old. The Housing Pilot is testing out how enhanced housing support for teenage parents can improve outcomes for them and their children, particularly in relation to child poverty. The pilot is running in seven areas: Somerset, Brighton \& Hove, Wandsworth, Nottingham, Worcestershire, York and Blackburn with Darwen.

6.6 The recommended measures in the Teenage Pregnancy Self Assessment Toolkit are designed to help areas robustly monitor the necessary contributions across the range of services. The toolkit also makes clear how progress on improving outcomes for teenage parents will contribute to a number of National Indicators including those within the LAA, for example 16-18 year olds who are NEET and the number of vulnerable people achieving independent living; and to Vital Signs in the NHS Operating Framework, for example early access for women to maternity services, the prevalence of breastfeeding at 6-8 weeks, and infant mortality (as part of all age, all cause mortality).

6.7 Many areas have successfully implemented support strategies, integrating them across different plans of relevant partner agencies, as illustrated in the examples from Staffordshire and Leicestershire.

In Leicestershire, to accelerate progress on increasing participation of teenage mothers in learning, an EET Strategy has been developed with Connexions as a key partner. It includes a robust dataset and a new referral system. The learning offer ensures that there is a range of provision, with the full engagement of Children's Centres.

In Staffordshire a Support Service for Young Families (SSYF) is now part of IYSS as a key element of Targeted Youth Support provision, with the multi-agency team benefitting from seconded posts from Education Welfare and Connexions Staffordshire. SSYF works with teenage parents until they are confident on their chosen path and in touch with mainstream services. 
6.8 To further improve outcomes for teenage mothers and young fathers we will, through guidance to local areas, make clear the importance and cost benefits of including teenage parents in the needs assessment and commissioning of IYSS, TYS, early intervention and parenting strategies.

6.9 We will continue to support teenage parents to continue education or work based learning, by continued childcare funding in 2010-11 through the Care to Learn scheme. An independent survey found 73 per cent of teenage parents said they could not have gone into any learning without Care to Learn support and 75 per cent gained a full or partial qualification from their course. Overall, only 27 per cent of Care to Learn recipients were NEET at the time of interview, compared with $\mathbf{6 6}$ per cent before taking a course. ${ }^{25}$

6.10 We will also strengthen the coordinated support for teenage parents, by continuing the Activity Agreement and Entry to Learning pilots during 2010-11. The pilots are testing methods to support vulnerable young people, including teenage parents, back into learning and will form the basis of learning and support agreements under measures to prepare for the raising of the participation age (c.f Investing in Potential. Dec 2009). Young people sign an agreement setting out the weekly activities that they will undertake to get back into learning and the additional support they will receive from their personal adviser. In weeks when they complete their activities, they receive a $£ 30$ payment.

6.11 We will continue to expand the number of areas implementing the Family Nurse Partnership. A group-based model of FNP will also be tested as part of the antenatal education programme, Preparing for Pregnancy, Birth and Beyond. This will be offered to parents needing additional support, including teenage parents, who don't qualify or choose not to participate in FNP.

6.12 Finally, we will evaluate the Teenage Parents Supported Housing pilot, to identify the most effective models of support. The results of the pilot will help to inform effective commissioning of supported housing for teenage parents following the Prime Minister's announcement in 2009 that all 16 and 17 year old parents provided with housing at public expense should receive support. The learning will also inform joint guidance with CLG on how to best provide support for teenage parents in housing need. 
The Wandsworth teenage parents supported housing pilot is delivered by Children's Services and Housing Departments, in collaboration with health and education. The modular training package, provided alongside intensive one to one support has enabled many teenage parents previously disengaged from learning, to develop and enjoy job related skills such as IT, hairdressing, mechanics and cooking, with some already moving on to college.

\section{Consultation questions}

- What are your local priority actions to improve outcomes for teenage mothers and young fathers?

- Are there any national actions that could be taken to help you accelerate progress?

- What existing local arrangements for involving teenage mothers and young fathers could be used to ensure local support services are meeting their needs? 


\section{Chapter 7: Getting delivery right - performance management of local teenage pregnancy strategies}

7.1 Our continuing strong commitment to the priority of teenage pregnancy is signalled in the inclusion of the under 18 conception rate as one of the five leading indicators in Public Service Agreement 14 and as a Tier 2 Vital Sign for PCTs in the NHS Operating Framework for 2010/11.

7.2 We have been very encouraged that this national commitment has been mirrored locally with up to 107 out of 152 local authorities choosing teenage pregnancy as one of their up to 35 Local Area Agreement (LAA) priorities - the second most popular LAA indicator. For local authorities this reflects senior leaders' awareness of the importance of reducing teenage pregnancy - and supporting teenage parents - for the individual young person, the economic benefits and the contribution to other priorities including narrowing health inequalities and tackling child poverty. As a Tier 2 Vital Sign, reducing the under 18 conception rate is a national priority for local delivery across all PCTs.

7.3 But while priority and strategic leadership at a senior level is critical in both the LA and the PCT, for local strategies to be effective, the commitment to reducing teenage pregnancy has to be translated into actions, with the specific contribution of each partner agency included in the relevant plans and within an area's Sustainable Community Strategy. This requires robust performance management and clear accountability by each partner agency, through to the Children's Trust Boards and Local Strategic Partnership.

7.4 To help areas further strengthen their performance management arrangements on both reducing under 18 conception rates and improving outcomes for teenage parents, we have provided a Teenage Pregnancy Self Assessment Toolkit. The toolkit focuses on tangible measures of strategy inputs, processes, and where possible, outcomes, so areas can monitor more objectively how the different strands of the Strategy are being implemented and identify priority actions. The toolkit includes a one page self assessment summary, for sign off by senior officials in the LA and PCT and accountability to the LSP. Whilst the toolkit is not compulsory we encourage all areas to complete the self assessment process to inform planning, with each agency taking responsibility for contributing data for the relevant performance measures.

\subsection{Government Offices and Strategic Health Authorities continue to play a key} role in identifying areas off track, helping them 'diagnose' the problem with their strategy implementation and providing support to strengthen delivery. Areas that are significantly off trajectory, have also benefited from a visit from the DH National Support Team. The National Support Team, working with the Regional Teenage Pregnancy Co-ordinators, provides each area with consultancy-style expertise, make recommendations on improving strategy implementation and offer some tailored intensive support following the visit. Several areas, such as Stoke, Enfield and Haringey, have already shown the impact of this more intensive focus with rates beginning to decline. 
7.6 To help local areas develop the most resource efficient and effective way of monitoring and performance managing their strategy delivery, we will identify a core set of measures from the wider set of indicators in the Self Assessment Toolkit and Sexual Health Balanced Scorecard. These can be used by Children's Trust Boards, in their new statutory status from April 2010, to monitor progress and inform their needs assessment and annual review of Children and Young People's Plans.

7.7 It is important that LAs and PCTs make the necessary contribution to teenage pregnancy in their relevant plans (for example within the LAAs and in the Sustainable Community Strategy) and ensure that strong performance management arrangements are in place for delivery against those plans. To support this, DH and DCSF will write to SHAs and GOs to reiterate the importance of bringing down rates of teenage conceptions.

\subsection{To provide effective challenge and support, DCSF and DH will continue to work with SHA and GOs to support improved delivery using relevant data to highlight areas of concern.}

\subsection{To strengthen the support we provide to local areas, we will review with GOs, SHAs and National Support Team the common themes of strategy} weaknesses. This, together with the responses we get from this strategy consultation, will help inform how we provide areas with the most effective and cost efficient support to improve delivery.

\section{Consultation questions}

- What are the local levers for improving delivery of the teenage pregnancy strategy and how do we make maximum use of them?

- What level of local progress in reducing teenage pregnancy do you feel is realistic but ambitious?

- Are there aspects of the Strategy which you feel need strengthening?

i) Joint commissioning of services to deliver the teenage pregnancy strategy

ii) Sharing and effective use of data

iii) SRE in schools

iv) SRE in FE colleges

v) Improving access to effective contraception and condoms

vi) Improving sexually active young people's use of effective contraception and condoms

vii) Workforce training on SRE

viii) Support for parents

ix) Embedding teenage pregnancy actions into early identification and IYSS

$x$ ) Supporting teenage parents.

- What current external support do you find helpful in delivering effective work on teenage pregnancy? 


\section{Annex 1: Consultation questions}

\section{Consultation questions: Local Authorities, PCTs and wider stakeholders}

Section 2: Why teenage pregnancy matters and what works

- How has teenage pregnancy been prioritised in your area?

- Have there been any challenges in prioritising work on teenage pregnancy?

- How are you joining work on reducing teenage pregnancy and supporting teenage parents with your local priorities?

Section 3: Knowledge and skills

-What are your local actions to improve children and young people's knowledge and skills on relationships and sexual health through: SRE in schools, FE, parents, and the wider workforce?

- How are you measuring the impact this has had?

- Are there any national actions that could be taken to help you accelerate progress?

- What existing local arrangements for involving young people could be used to ensure the SRE - in schools and other settings - are meeting their needs?

Section 4: Contraception

- What are your local actions to improve sexually active young people's access to effective contraception and condoms?

- What are your local actions to improve sexually active young people's use of effective contraception and condoms?

- Are there any national actions that could be taken to help you accelerate progress?

- What existing local arrangements for involving young people could be used to ensure local contraceptive and sexual health services are meeting their needs?

Section 5: Early support for young people most at risk

- What is working well on early identification and support for young people at risk of pregnancy?

- Is CAF being systematically used?

- How are you measuring impact of early intervention and support for young people most at risk of pregnancy?

Section 6: Supporting teenage parents

- What are your local priority actions to improve outcomes for teenage mothers and young fathers?

- Are there any national actions that could be taken to help you accelerate progress?

- What existing local arrangements for involving teenage mothers and young fathers could be used to ensure local support services are meeting their needs? 
42 Teenage pregnancy strategy: beyond 2010

Section 7: Ensuring effective delivery

- What are the local levers for improving delivery of the teenage pregnancy strategy and how do we make maximum use of them?

- What level of local progress in reducing teenage pregnancy do you feel is realistic but ambitious?

- Are there aspects of the Strategy which you feel need strengthening?

i) Joint commissioning of services to deliver the teenage pregnancy strategy

ii) Sharing and effective use of data

iii) SRE in schools

iv) SRE in FE colleges

v) Improving access to effective contraception and condoms

vi) Improving sexually active young people's use of effective contraception and condoms

vii) Workforce training on SRE

viii) Support for parents

ix) Embedding teenage pregnancy actions into early identification and IYSS

$x)$ Supporting teenage parents

- What current external support do you find helpful in delivering effective work on teenage pregnancy? 


\section{Annex 2: Case studies}

\section{Consulting young people on SRE}

In 2009, Walsall Children's Services, Serco, NHS Walsall and Walsall Council completed a large scale consultation with young people about the delivery of SRE in their schools.

Walsall adapted the Sex Education Forum's SRE pupil consultation resource Are You Getting it Right? to enable all children from Key Stage 1-4 to be consulted. This resulted in over 13,000 children and young people participating. In summary, the consultation found:

- Pupils would most like their class teachers to deliver SRE.

- The following topics to be taught received the highest scores

- Years 1 and 2 - Keeping clean and friendships

- Years $3,4,5$ and 6 - Friendships and dealing with your feelings

- Years 7 and 8 - Friendships and confidence

- Year 9 - Other emotions and safe sex

- Year 10 - Safe sex and contraception

- Year 11 - STIs (sexually transmitted infections) and emotions.

- The most popular methods of delivery were DVD and TV programme.

To make maximum use of the consultation, Walsall Children's Services, Serco have agreed the following actions:

- Disseminate the findings to all schools so that in consultation with the relevant PSHE Advisor they can adapt their individual SRE curriculum and policy.

- Recommend all schools to consider who delivers SRE and what resources will enhance teaching and learning of SRE in their school.

- Align the findings to the Enhanced Healthy Schools Model.

- Provide training to PSHE leads in order to ensure findings influence change and impact on practice.

- Share the findings with a wider audience of partner agencies and practitioners, especially those involved in the delivery of SRE in the borough or those who commission teenage pregnancy work.

- The findings will be shared with Walsall school Governors and head teachers to help them prepare for statutory PSHE in 2011 (subject to legislation), and ensure the SRE meets the needs of their students.

For more information, contact: diane.osborne@walsall.nhs.uk 


\section{Targeted SRE with vulnerable young people}

' $L 8 \mathrm{R}^{\prime}$ ' is an award winning education project that integrates interactive drama on video and the web, access to advice \& information and online mentoring, as well as practitioner \& peer educator training. The project has been running since 2004 , and the core learning resource now comprises $10 \times 10 \mathrm{~min}$ TV drama episodes which are designed to challenge attitudes and awareness on key themes including; sex and relationships, sexual health, early parenthood, drugs \& alcohol, emotional wellbeing, peer pressure, gangs \& youth crime. Young people lead on development of stories $\&$ characters in the drama, as cast and virtual cast, online mentors and moderators, and as youth editors on L8R social media pages.

In the current year L8R has partnerships with 25 Local Authorities and PCTs. As well as some 300 schools, over 100 PRUs, Special Schools, settings with Looked After Children, Youth Projects and Youth Offending Teams are registered with L8R. A 2006 national evaluation report said:

\section{"L8R is used with some success in youth settings and referral units. Practitioners in these settings value the resource as a way to address sensitive topics with hard to reach young people. They have been able to point to information and generate discussion on issues which were difficult to broach otherwise... The flexibility and relevance of the resource and relevance of the storylines are key to engaging young people with a broad range of experience and backgrounds."}

As well as ongoing development of the core resource, L8R is currently the focus of outreach projects with 'at risk' young people including; a film-making programme with three PRUs in Camden where young people develop their own stories out of the L8R episodes; a peer educator training programme with young offenders in Lambeth where they use the episodes to educate on gang and youth crime issues in schools and PRUs.

For more information, contact John White at Hi8us: john@hi8us-south.co.uk

\section{Integrating Speakeasy into local parenting strategies}

The engagement of parents is an integral part of Stockport's Teenage Pregnancy and Parenting Strategies. The Speakeasy programme has been a crucial part of the delivery of the strategies. It was started in 2005 with a small group of trained facilitators located within the Sure Start areas. Speakeasy is now part of a 'core offer' to priority schools alongside an SRE programme called 'Bodywise' and a parenting programme called 'Surviving Teenagers'. Parents of teenagers as well as pre-teenagers from schools, who live in our hot spot areas, are able to access the programmes. The programme has been a very welcome addition to the schools pastoral programmes and many parents have taken up the option to have their learning accredited by OCN. To date 158 parents have attended the Speakeasy programme, with 118 achieving accreditation. 
Through the informal evaluation of the programme, parents have reported how they and their children have benefitted from the Speakeasy programme, with 'word of mouth' approach contributing to its success. A more comprehensive evaluation is planned this year.

To embed a sustainable programme a 'training the trainer' model was adopted. Currently, over 30 facilitators have trained our local trainers. The facilitators run approximately six courses each school term, some of which are targeted to specific groups. The facilitators are drawn from a range of professional backgrounds including Parent Support Advisors, Learning Mentors, Community Outreach Workers via social care, FIP workers and health professionals

The multi-agency partnership of the Parenting Team, Community Outreach Team (COT) and a Parent Support Advisor teamed up with the Young Parents Project to provide a Speakeasy course for the young parents in Stockport. The Stockport Young Parents Project was set up to work with teenage parent's age 16 to 19 to support them in returning to education, training or employment.

For young parents, Speakeasy has a number of benefits. Preparing them with the knowledge and confidence to talk to their own children as they grow up, gaining a learning accreditation and increasing their own awareness of sexual health and contraception.

For more information, contact: barbara.swann@ntlworld.com

\section{Workforce training on relationships and sexual health}

Research with 1000 young people in Warwickshire showed that the majority saw the role of Youth Support Workers as an important source of information regarding relationships and sexual health. This finding and consultation with professionals led to the development of a Relationships and Sex Education (RSE) policy and workforce training programme. County-wide policy and guidance was agreed, bringing together previously separate policies for Connexions and the Youth and Community Service (IYSS) and for Social Services. This County-wide was adopted by all those organisations wishing to embark upon the workforce training programme.

A four-tiered training programme was developed to implement the policy, delivered in partnership between NHS Warwickshire and Warwickshire CC under the umbrella of the local 'Respect Yourself' Campaign (RYC) which covers:

- a general introduction to supporting young people including the Respect Yourself Campaign's key messages, sex and the law, attitudes and values and basic signposting;

- delay messages;

- further knowledge and information to support one to one interventions and group work with young people; and

- condom distribution and more recently, chlamydia screening. 
Over 1000 professionals have attended RYC training and/or conferences and 350 professionals from a variety of backgrounds, including Education, IYSS, Leisure Services, Police and Voluntary Sector, are trained up to Level 3 (Warwickshire's Condom Distribution Protocol).

Under 18 conception rates have been slowly but steadily declining in Warwickshire but in one borough rates were higher than the national and county rates and were not falling. This resulted in a mapping exercise using the 'what works' criteria and as a result workforce training was prioritised and frontline workers received the training as a priority. Between 2006 and 2007, the area saw its first decline in the under 18 rate since the inception of the strategy - a fall of 24.6 per cent and anecdotal information and local data show that this decline is still continuing.

The workforce training programme for professionals is seen as an integral part of the Respect Yourself Campaign work and is evaluated positively by all that access it and the young people that ultimately benefit from it. Warwickshire is currently reviewing its training to ensure that progress accelerates the achievement of targets regarding both the HIV \& Sexual Health and Teenage Pregnancy Strategies, but will remain focused on the achievement of positive outcomes for young people.

For more information, contact: amydanahay@warwickshire.gov.uk

\section{Reducing Unplanned Repeat Pregnancies in Hackney}

Hackney was one of four sites across England which took part in Department of Health's Teenage Health Demonstration Site programme to improve accessibility for teenagers to local health services. A key area of focus in Hackney was reducing repeat conceptions for which a new post was developed, the Assertive Outreach Health Nurse. The primary purpose was proactively preventing repeat conceptions and addressing the contraceptive needs of under $18 \mathrm{~s}$ who had either had a live birth, termination of pregnancy (TOP), miscarriage or who were pregnant. This included an emphasis on LARC (Long Acting Reversible Contraception) methods.

Referral pathways were established with a wide number of services including local TOP provider, midwifery and acute services, looked after children (LAC), social care and youth services, Hackney Young Families Support Service, school nurses, health visitors and community sexual health services.

Young people referred under the scheme are offered an appointment at a time and location convenient to them which can be in their home, school, local children's centre or health centre or even a local café. All methods of contraception are discussed and a contraceptive plan is developed. If a home visit takes place, most methods of contraception can be provided including the Depo-Provera injection and fitting of implants. 
Key aspects of the Assertive Outreach Health Nurse role include being flexible, having patience, perseverance, being young people friendly and responding to the needs of a group of young women who are often hard to reach with chaotic lives. A lot of the work includes teaching the young person about contraception methods and trying to dispel myths they may have heard regarding them. By ensuring that young people have appropriate counselling regarding different methods especially LARC, the more likely they are to continue with that method or return for help if experiencing any side effects. The nurse encourages young people to keep in touch via mobile phone and text messages are widely used to remind young people when their next appointment or next injection is due.

In Hackney, between 2006-07, the number of repeat abortions to under 18s declined from 41 to 29 . This encouraging reduction corresponds with the appointment of the Outreach Nurse.

For further information, contact: nicola.baboneau@learningtrust.co.uk

\section{Young people friendly health centre in Bradford}

The Ridge Medical Centre, in Little Horton, Bradford provides a welcoming space for young people with a strong young people friendly ethos amongst all staff. The practice is a new build, including GP surgeries, and ensured that young people were involved in the design of a specific youth space and provides feedback to them about suggestions they have made. It is one of the first Health Services in West Yorkshire to achieve You're Welcome status.

Messages communicated to young people include that they are able to attend with or without a parent or carer or with a friend and that staff will always aim to help them feel comfortable when asking about personal issues such as sexual health.

As a minimum, the practice offers an additional drop in service to access sexual health services one day per week which is available to both young people who are registered and not registered with the practice. The practice offers a wide range of contraception provision and STI treatments. Young people are actively involved in the Practice's patients group. Anne Connolly a GP at the Centre said "We aimed to achieve You're Welcome status because we wanted to ensure that we were doing all that we could to deliver a service that is appropriate and acceptable to Young People. We want young people to attend with confidence that they can trust us. Even though we have achieved You're Welcome status we view communicating well with young people and securing their participation as work that is ongoing, welcoming and inviting young people to have their say about the service".

For further information, contact: anne.connolly@bradford.nhs.uk 


\section{Young people involvement in Sexual Health Service reviews}

As part of the support offered to local areas Government Office for the NW and NHS North West worked collaboratively to undertake a service improvement review with a local area. The purpose of the review:

- To review the current service provision, identifying gaps and gaps to delivery and access.

- To use the Sexual Health Needs Assessment to develop a set of service reviews and recommendations to inform commissioning process.

- To develop clear plans for service improvements with commissioners and providers.

- To involve young people in the service review.

- To identify potential areas of innovation and emerging good practice.

Part of the brief for the review was to gain insight from young people to inform service improvement plans. To gain objective young people's perspectives, Young Advisors from a different local area were commissioned to undertake a mystery shopping exercise targeting sexual health services. Knowsley Young Advisers had a wealth of experience and were commissioned as the Mystery Shoppers.

Using the You're Welcome quality criteria as a guide, the Young Advisors were asked to provide feedback on services in a variety of settings in the local area on:

- Accessibility of EHC, pregnancy, LARC and Chlamydia screening.

- How easy was it to get to the service.

- Were there any barriers? If so, what were they?

- Was the experience good? If so, why? If not, why not?

- Did you get what you needed?

- What could be improved?

- What would they like the service to provide?

- Who would they like them to provide this?

As part of the review process, the Young Advisors attended a workshop with key professionals from the Local Authority and PCT to feedback their findings and recommendations from their visits. The following key recommendations emerged:

- The need for increased access to 'drop in' type services.

- Greater access to service provision including availability in the evenings and at weekend.

- The need to involve young people in the design, delivery and review of sexual health services.

The mystery shopper exercise has led to a number of planned service developments to improve access to young people friendly sexual health services with an emphasis on contraception, using You're Welcome as a vehicle for service improvement.

For more information, contact: wendy.nicholson@dh.gsi.gov.uk 


\section{School based health service with You're Welcome accreditation}

Based in an area of real deprivation, Bispham High School - Arts College in Blackpool was facing some significant challenges around teenage pregnancy rates, binge drinking, substance misuse and mental health issues. Three years ago, building on the frameworks provided by the You're Welcome quality criteria and the National Healthy Schools Programme, NHS Blackpool appointed a staff nurse as a Health Mentor to work full-time in the school. The focus was to set up a school based health service that would help support students and the staff team in addressing some of these issues.

A range of successful health interventions and policy updates have been introduced, with the national guidance helping to provide a clearer direction and focus for improvement. External agencies and specialist outreach workers are now providing support on a range of health issues, inside the classroom and through drop-in clinics. This has increased the accessibility of appropriate advice and referrals into targeted agencies such as alcohol and substance misuse services.

One example, the Connect sexual health clinic, now visits the school on a weekly basis, and over 440 students have accessed the service in the last academic year alone. In the two years since the introduction of this service, only one student pregnancy has been recorded, compared to 16 in the previous two years.

Over the three years in which the school has had a full time health mentor in place, there has been a significant change at the school. Attainment levels have risen, with a 20 per cent improvement in exam results over this period. The school has also been highly recommended by Ofsted for its approach to health and wellbeing, and was named "one of the most improved schools in the country" by the Specialist Schools and Academies Trust in 2008.

Having experienced the positive impact upon the whole school community firsthand, staff at Bispham High School - Arts College are really recognising the value of providing easy access to health advice and interventions in school, and are even beginning to facilitate some of these support services themselves. Furthermore, NHS Blackpool is planning to introduce full time Health Mentors into all local schools to replicate this success more widely. The School achieved Healthy School status in December 2007. In March 2009 the on-site health service was one of the first to be nationally accredited as meeting the You're Welcome quality criteria for making health services young people friendly.

For further information, contact: margaret.singleton@bispham-high.blackpool.sch.uk 


\section{Improving Access to Contraception: North of Tyne}

Improving access to and uptake of contraception amongst young people is one of the main priorities in the strategy to reduce rates of unintended conceptions amongst teenagers in North of Tyne (covering Newcastle, North Tyneside and Northumberland PCT). There is a particular focus on improving uptake of Long Acting Reversible Contraceptives (LARCs) and funding was secured in 2008/09 to implement this work which has five broad areas including:

\section{Improving Access to LARC in Primary Care}

A Local Enhanced Service (LES) for LARC in Primary Care has been developed. The LES provides an additional payment for insertion to under 19s. An electronic reporting tool and database are being developed to improve performance monitoring against the LES and monitor trends in uptake. Funding secured from the Strategic Health Authority has enabled the appointment of GP Champions in sexual health. Progress to date includes:

- 26 Primary Care staff have completed theoretical training on implant insertion practical support is ongoing.

- More than 60 per cent of practices across the patch have signed up to the LES to deliver the services.

- Designated sexual health leads are being identified in each practice to facilitate effective communication and provide a point of contact for developing sexual health services within the practice.

\section{Improving Access to contraception in Community Pharmacies}

Building on the successful free EHC scheme offered through community pharmacies a Local Enhanced Service for LARC (Implants and injectables) has been developed in six pharmacies. A robust training programme has been developed and training is underway. Chlamydia Screening, treatment and onward referral into contraception services is also included. Pharmacies participating in the scheme are those located in an area of high teenage conception rates with limited availability of other contraceptive services, with a good uptake of free emergency contraception in under $18 \mathrm{~s}$.

\section{Targeted outreach}

A peripatetic nurse led LARC service has been established in each of the areas. The services work as part of the existing sexual health service delivering services in a range of locations to ensure reach to those identified as being at increased risk of early unintended pregnancy including women's homes, homeless projects, LAC, Youth and community and FE and school settings. Early indications suggest that LARC uptake amongst women accessing these services is higher than those accessing mainstream contraceptive provision. 
Reducing unintended repeat conceptions

Improving access to ongoing sexual health advice and support for women having a baby or undergoing an abortion is included in CQUIN North of Tyne. This is facilitating partnership working and the development and review of care pathways for women.

Nurses involved in the provision of abortion services have been provided with training and support to enable them to provide women with a choice of contraceptives prior to discharge. Provision of LARC has increased and the percentage of women being discharged with no method is reducing.

Improving Access in FE Colleges

All three FE colleges North of Tyne provide weekly sexual health drop ins which are delivered by nurses from the local sexual health service. All sessions provide pregnancy testing and referral, contraceptive advice treatment and support (two of which include implants), C- card and Chlamydia screening. All three settings are working towards You're Welcome accreditation.

For more information, contact: judith.stonebridge@northoftyne.nhs.uk

\section{Early identification and support for young people at risk}

Following the revision of the Teenage Pregnancy Strategy in 2007, Stoke-On-Trent City council appointed six dedicated Teenage Pregnancy Prevention Officers to work with young people at risk of becoming teenage parents. In order to properly identify young people at risk, a screening toolkit was developed. Training on the toolkit has been rolled out to almost 500 front line professions including schools, Education Welfare Officers, Youth Offending Officers, Youth Service, Connexions, school staff and many more.

Although the toolkit has been designed to identify young people at risk of becoming teenage parents, a large number of the risk factors are generic, enabling us to identify young people who are vulnerable and in need of targeted support. The Prevention Officers offer one to one support, group sessions, and drop in sessions in schools, particularly as part of the multi agency centres (MACs Place) that we are rolling out across secondary (initially) school settings. The team provide sexual health advice and support, including condom distribution, and support young people to clinic appointments where necessary. They carry out work around improving young peoples self esteem and confidence, and act as lead professional to ensure that any issues identified through the screening toolkit are addressed utilising multi-agency integrated support (i.e. housing issues, NEET status, school attendance and many more). By providing co-ordinated packages of support (IYS) for young people we are able to address a number of issues through the same process rather than agencies working alone, which is not the best use of resources and can lead to duplication of work and confusion for young people. 
The multi agency centres (MACs Place) offer drop in facilities from a range of different agencies offering different support and services e.g., Prevention Team, Connexions, Youth Service, mental health services, young carers service, Police, and many more. One of the primary functions of MACs is to identify young people at risk in order to provide integrated targeted support where required.

Since the Prevention Team were appointed in September 2007 they have provided targeted youth support to 272 'high risk' young people on an intensive caseload, and have supported more than 930 young people identified as 'low to medium risk' through group work intervention. Of those supported through intensive one to one support only 13 have gone on to become pregnant.

The under 18s conception rates in Stoke have been an area of concern for some time, resulting in a complete revision of the Strategy in 2007. Recent data for the last quarter 2007 and data for 2008 shows a very encouraging decline. Having analysed the activity during this time period we have identified that the timeline for the appointment of the Prevention Officers correlates directly with the reductions in conceptions from the same period in 2007.

For more information, contact: tracy.kirk@stoke.gov.uk

\section{Supporting young parents into education, employment and training}

Leicestershire Teenage Pregnancy Partnership places a high priority on supporting teenage parents into learning which has enabled them to achieve an above average level of participation of 35 per cent in Education, Employment and Training (EET) for mothers aged 16-19.

To accelerate performance and to ensure achievement of a participation rate of 60 per cent of mothers aged 16-19 EET by December 2010 an EET Strategy for Teenage Parents has drawn together the key priorities to ensure teenage parents receive the best possible support across both a range of services and the whole county. A key partner in this development is the local Connexions Service which through their Teenage Pregnancy Coordinator post has led the way on developing the EET Strategy a key part of which is ensuring parity of learning and support provision across Leicestershire.

The EET Strategy includes actions to ensure a robust dataset and has launched a new referral system for young parents interested in taking up a learning opportunity. Lead posts within Connexions and the Youth Service ensure that key service areas are working successfully to engage and support young parents and the specialist Teenage Pregnancy Midwifery team link young women into other agencies for support via a data sharing protocol.

The learning 'offer' ensures that there is a range of provision available to meet the needs of young parents reflecting their different circumstances, for example, accredited learning programmes such as Young Mums to be. Support and learning opportunities are marketed directly to them through a Progress Brochure developed by young parents themselves. Children's Centres are fully engaged in delivering 
support for young parents, including investment in specialist outreach worker posts. A recent marketing development is a publication challenging negative stereotypes and acknowledging the achievements of teenage parents often in difficult circumstances which as secured a contribution from author Sue Townsend. It will be launched in March 2010.

For further information, please contact: Katie Phillips, Leicestershire Teenage Pregnancy Co-ordinator: katie.phillips@leics.gov.uk

\section{Integrated support for teenage parents}

The Support Service for Young Families (SSYF) in Staffordshire has been developed in recent years as a pivotal contributor to the support network for pregnant teenagers and teenage parents with funding through the Teenage Pregnancy Implementation Grant (now part of Area Based Grant). It is now being made part of Staffordshire's Integrated Youth Support Service (IYSS) as a key element of Targeted Youth Support (TYS) provision.

The key principle of the SSYF Team is multi-agency planning, greatly enhanced by seconded posts to the Team from Education Welfare and Connexions Staffordshire. These secondments have provided expertise to support young people's engagement in education, employment and training (EET) and have resulted in good information sharing about teenagers and their aspirations for use in casework sessions.

Young parents are supported to remain in EET during pregnancy and to return to EET following time off to bond with their baby. If young mothers want a longer period off with the baby, EET is still discussed and actively promoted for the future.

The SSYF workers plan with the teenagers and service providers a pathway to learning and access to associated support. Care to Learn and Education Maintenance Allowance are actively promoted and the teenagers are assisted with form filling to apply for these. Help to explore and secure childcare is offered alongside navigation through possible benefit entitlements. The SSYF worker, via the multi-agency working relationship with providers and programmes, can mediate on behalf of teenagers to ensure that the process runs smoothly. The Common Assessment Framework is appropriately used to ensure a team is around the Child for the most vulnerable of young people.

The issue of second or repeat pregnancies is also addressed as all staff have been trained and equipped to undertake post natal contraception choice advice.

SSYF offers support to a teenager until both parties feel confident that the teenager was succeeding in their chosen pathway and that access to, and use of, mainstream services was established. At this point the teenager's vulnerability is de-escalated and the targeted support of the SSYF can be withdrawn with the option for the teenager of re-engaging if necessary.

For further information, contact: sue.mulroy@staffordshire.gov.uk 


\section{Teenage Parents Supported Housing pilot}

The Teenage Parent Supported Housing pilot aims to provide enhanced housing support to improve outcomes for teenage mothers, young fathers and their children. It's developing an evidence base of successful approaches to tackling the housing issues faced by teenage parents and their engagement in learning, potentially transferable to other LAs. The pilot is running in 7 LAs (Blackburn with Darwen, Brighton and Hove, Nottingham, Somerset, Wandsworth, Worcestershire and York) until March 2011 and is funded through the Child Poverty pilot programme announced in Ending Child Poverty: Everybody's business (DCSF, DWP and HMT, 2008).

In Wandsworth, the pilot assists young parents aged 16-18 to maintain healthier lifestyles with an emphasis on emotional wellbeing. It aims to improve their skills in sustaining accommodation by providing a modular training package alongside intensive one-to-one support for young parents at risk of losing their tenancies. It's being delivered by the Council's Children's Services and Housing Departments, working in close collaboration with health services, local housing associations, school and colleges.

The impact so far has been that young parents, often with chaotic life styles and not engaged in learning prior to their engagement in the pilot, report positive engagement with courses in job related skills such as IT, hair and beauty, mechanics and practical household skills such as cookery. Some have moved on to college.

The pilot has resulted in strong links with housing providers which is critical to success in sustaining engagement of young parents.

Commenting on her experiences of the courses on offer, one young mother said:

"Doing the IT course was good for me as I could build up my skills in a short time and don't have to worry about not having time for the children. If I hadn't started the IT course, I don't think I would have had the confidence to apply for the course I am on at [college] now as they had rejected me before. I know that I can do it now."

The Pilot is being externally evaluated by a research team lead by the University of York, Centre for Housing Policy. The findings will help inform how the Prime Minister's commitment on housing support for parents aged 16 and 17 needing to access publicly funded housing will be taken forward in the most effective way.

For further information on the Wandsworth Pilot, contact pjhugroo@wandsworth.gov.uk; and on the Housing Pilot, contact: jo.gunner@dcsf.gsi.gov.uk 


\section{Endnotes}

\section{Chapter 1: What has changed since 1998?}

1 Office for National Statistics, 2008 Under-18 conception data, published February 2010.

2 Unpublished DCSF analysis.

3 Teenage Pregnancy Unit analysis of ONS data.

4 Labour Force Survey data, 1997-2009.

5 Unpublished campaign tracking survey, DCSF (2009).

6 Young People's survey of sex and relationships education, Sex Education Forum (2008).

7 Populus parents' poll, October 2009).

8 BMRB International, Evaluation of the Teenage Pregnancy Strategy: Report of results of benchmark wave (2001).

9 BMRB International, Evaluation of the Teenage Pregnancy Strategy: Tracking survey (2001).

10 National mapping of on-site sexual health services in education settings: Provision in schools and pupil referral units in England - Sex Education Forum, June 2008.

11 National Mapping Survey of On-site Sexual Health Services in Education Settings: Provision in FE and sixth-form colleges, Sex Education Forum, (2008).

12 Ofsted PSHE report 'Time for Change', April 2007.

13 Partner exploitation and violence in teenage intimate relationships', NSPCC (2009).

\section{Chapter 2: Why Teenage Pregnancy Matters}

14 Teenage Parents Next Steps, DCSF 2007.

15 Teenage Pregnancy Next Steps, DCSF 2006.

16 Emerging Answers: Research Findings on Programs to Reduce Teen Pregnancy and Sexually Transmitted Diseases - Kirkby 2007.

17 Explaining Recent Declines in Adolescent Pregnancy in the United States: The Contribution of Abstinence and Improved Contraceptive Use - Santelli, 2007. 


\section{Chapter 3: Knowledge \& Skills}

18 R U Thinking tracking survey, Wave 1 March 2007.

19 BMRB International Report: Teenage Pregnancy Strategy Evaluation, 2004.

20 'SRE: Are you getting it?' - UK Youth Parliament, 2007.

21 Teenage Pregnancy and Sexual Health Marketing Strategy. Department of Health and Department for Children, Schools and Families, 2009.

Chapter 4: Improving Access to Services

22 Marie Stopes International, 2009.

23 'Sexual Health, Rights and Staying Safe', UNICEF 2009.

\section{Chapter 6: Improving Outcomes}

24 Teenage Parents Next Steps - DCSF, 2007.

25 Impact of Care to Learn: tracking the destinations of young parents funded in 2006/07 and 2007/08, Vaid, L, Bell, L, Mavra L, Sims L - Centre for Economic and Social Inclusion and Learning and Skills Council (2009). 





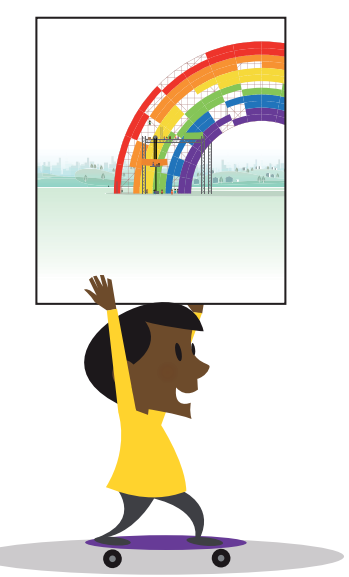

You can download this publication or order copies online at: www.teachernet.gov.uk/publications Search using the ref: DCSF-00224-2010

Copies of this publication can also be obtained from:

Department for Children, Schools

and Families Publications

PO Box 5050

Sherwood Park, Annesley

Nottingham NG15 ODJ

Tel 08456022260

Fax 08456033360

Textphone 08456055560

Please quote ref 00224-2010DOM-EN

ISBN: 978-1-84775-686-2

$\mathrm{PPBHP} /(4287) / 0210$

\section{(c) Crown Copyright 2010}

The text in this document (excluding the Royal Arms and other departmental or agency logos) may be reproduced free of charge in any format or medium providing it is reproduced accurately and not used in a misleading context.

The material must be acknowledged as Crown copyright and the title of the document specified.

Where we have identified any third party copyright material you will need to obtain permission from the copyright holders concerned.

For any other use of this material please contact the Office of Public Sector Information, Information Policy Team, Kew, Richmond, Surrey TW9 4DU or e-mail: licensing@opsi.gsi.gov.uk

\section{$75 \%$ recycled}

